\title{
Mother-Offspring Relations: Prey Quality and Maternal Size Affect Egg Size of an Acariphagous Lady Beetle in Culture
}

\author{
Eric W. Riddick and Zhixin Wu \\ National Biological Control Laboratory, USDA-Agricultural Research Service, 59 Lee Road, Stoneville, MS 38776, USA \\ Correspondence should be addressed to Eric W. Riddick, eric.riddick@ars.usda.gov
}

Received 10 January 2012; Revised 21 March 2012; Accepted 9 April 2012

Academic Editor: Michael Rust

Copyright ( $\odot 2012$ E. W. Riddick and Z. Wu. This is an open access article distributed under the Creative Commons Attribution License, which permits unrestricted use, distribution, and reproduction in any medium, provided the original work is properly cited.

\begin{abstract}
We investigated mother-offspring relations in a lady beetle Stethorus punctillum Weise that utilizes spider mites as prey. Our objectives were to determine if (1) prey quality affects egg size, (2) maternal size correlates with egg size, and (3) egg size affects hatching success. We fed predators spider mites Tetranychus urticae Koch from lima bean Phaseolus lunatus L. foliage in the laboratory. Mothers of unknown body size offered high rather than low quality spider mites since birth produced larger eggs. Mothers of known body size offered only high quality spider mites, produced eggs of variable size, but mean egg size correlated positively with hind femur length. Mothers laid their eggs singly, rather than in batches, and eggs were large relative to femur size. Egg size did not affect hatch success; mean hatch rate exceeded $95 \%$ regardless of egg size. In conclusion, the quality of prey consumed by $S$. punctillum mothers while in the larval stage can affect their size as adults and, consequently, the size of their eggs. The behavior of laying eggs singly, the positive relationship between maternal size and mean egg size, and the high rate of egg hatch suggest that $S$. punctillum mothers invest heavily in offspring.
\end{abstract}

\section{Introduction}

Maternal investment in offspring is a major topic that has intrigued zoologists for years [1]. Trade-offs between allocating limited resources to offspring rather than to extending the lifespan of the mother exist [2]. Researchers commonly use offspring (egg) size as an estimate of the amount of resources allocated to offspring [3]. In fact, life history theory predicts that there is a trade-off between egg number, that is, potential or realized fecundity, and egg size in a diversity of animals $[4,5]$.

One prominent factor that could affect egg size of a predator is the quality of prey available to the mother. Mothers that consume high quality prey should maximize the amount of resources allocated to their offspring [2]; however, this is not always the case [6]. Presumably, mothers fed high quality prey should transfer essential nutrients into egg production rather than to general maintenance and survival. A number of studies attest to this assumption. Although evidence that prey quality affects egg size of predatory insects is not robust, the staphylinid beetle Tachyporus hypnorum $\mathrm{F}$. produced smaller rather than larger eggs when fed aphids of low quality rather than fruit flies of high quality [7]. Carabid beetles (Pterostichus melanarius Illiger, Pterostichus cupreus L.) produced larger eggs when fed a mixed diet of carbohydrates and protein rather than a diet of aphids alone [8]; apparently, a mixed diet was more nutritious for the species tested by Wallin et al. [8]. These two exemplary studies tested insect predators that lay eggs singly rather than in batches. There are no published records on the effect of prey quality on egg size of coccinellids that lay eggs singly rather than in batches. For coccinellids that lay their eggs in batches, consumption of low quality prey can result in a reduction in batch size [9]. Food stress (scarcity of aphids) can lead to a reduction in the size of egg batches, but not individual eggs within batches in the coccinellid Coccinella septempunctata L. [10].

Maternal body size may correlate with the size of progeny in animals. At an interspecific level, there is evidence that large-sized species produce small eggs, whereas small sized species produce large eggs relative to their body size [5]. This mother-offspring size relationship occurs between 
coccinellid species. For example, large-sized coccinellids, such as Adalia species and Coccinella species, produce small eggs relative to their body size, whereas tiny-sized Stethorus species produce large eggs relative to their body size $[9,11]$. Differences in egg size between small and large species might be an adaptation to the size of their prey and the size of prey aggregations on host plants [11-13]. It may also reflect the oviposition strategies of a species (i.e., degree of synovigeny, number of ovarioles present in a species, and rate of egg maturation). Note that egg-laying differences between species with distinct life histories could play a role in egg size variation. For example, acariphagous coccinellids such as Stethorus punctillum Weise and Stethorus punctum punctum (LeConte) lay their eggs singly rather than in batches [14]. In contrast, large-sized aphidophagous species such as Adalia bipunctata L. and C. septempunctata L. lay eggs in batches [15].

At the intraspecific level, body size of females of a given species can scale positively, negatively, or not at all with egg size [16-19]. When Kajita and Evans [20] combined data on five aphidophagous coccinellids, mean egg size (volume) related significantly to maternal body weight, with no significant relationship among species. Egg size does not correlate with body size in the carabid beetle Brachinus lateralis Dejean, an ecto-parasitoid of aquatic beetles [21], or in the colydiid beetle Dastarcus helophoroides Faimaire, an ecto-parasitoid of cerambycid beetles [22].

Intuitively, if large-sized eggs contain more essential nutrients than intermediate or small-sized ones within a species, the larger eggs should have the greatest fitness. However, egg contents do not always track along with egg size [23], and the amount of yolk provisioned within an egg could provide a more accurate estimate of maternal investment than egg size [1]. McIntyre and Gooding [23] showed that egg size correlated negatively or not at all to hatch rate in house flies. Egg size does not influence hatch time of C. septempunctata [10]. There are no other records on the effects of egg size on hatch rate in coccinellids. First instar larvae of two carabids, P. cupreus and P. melanarius, hatching from large rather than small eggs had longer survival rates [8]. In the staphylinid beetle Aleochara bilineata (Gyll.), larger first instar larvae survived longer and were more efficient at finding hosts than smaller-sized ones [24].

In this study, we examined the relations between maternal size and egg size in $S$. punctillum, a tiny lady beetle that utilizes spider mites as essential prey $[14,25,26]$. Our research objectives were to determine if (1) prey quality affects egg size, (2) maternal size correlates with egg size, and (3) egg size affects hatching success. This information will expand our knowledge of the life history strategies of predatory insects, especially coccinellids.

\section{Materials and Methods}

2.1. Plants and Arthropods. Lima bean Phaseolus lunatus L. were grown from seed in plastic planters $(57 \times 35.5 \times 16 \mathrm{~cm}$, $\mathrm{L} \times \mathrm{W} \times \mathrm{H})$ in an environmentally controlled greenhouse (at $27^{\circ} \mathrm{C}, 30-40 \% \mathrm{RH}$, and $18 \mathrm{hr}$ photophase) in Stoneville,
Mississippi, USA. In each planter was approximately $4 \mathrm{~g}$ of fertilizer (Osmocote, Smart-Release, The Scotts Company LLC) with $2.5 \mathrm{~L}$ of potting soil (Miracle-Gro, MoistureControl, The Scotts Company LLC), $2.5 \mathrm{~L}$ of coarse vermiculite, and water before adding seeds. We obtained twospotted spider mite Tetranychus urticae Koch adults from Syngenta Bioline (Oxnard, California, USA) and predator $S$. punctillum adults from Applied Bionomics Ltd. (Sidney, B.C. Canada). Male and female predators were placed together in clear plastic containers $(16 \times 12 \times 6 \mathrm{~cm}, \mathrm{~L} \times \mathrm{W} \times \mathrm{H}$, with screened lids). Their progeny was separated, according to stage of development (egg, larval, pupal, and adult) and reared in Petri dish arenas $(90 \times 25 \mathrm{~mm}, \mathrm{~W} \times \mathrm{H}$, with screened lids) in a growth chamber $\left(23^{\circ} \mathrm{C}, 60 \% \mathrm{RH}, 16 \mathrm{~h}\right.$ photophase).

2.2. Prey Quality and Egg Size. To determine the effect of prey quality on egg size, we reared predators from the time of egg eclosion on spider mites from one of two cultivars, Henderson Bush or Fordhook 242 lima bean. Spider mites ingest a much higher dose of linamarin when feeding on foliage of the Henderson cultivar than the Fordhook cultivar, and consumption of Henderson-fed prey causes a reduction in growth, development, and body size of $S$. punctillum larvae [27]. Therefore, we designated low quality and high quality prey as spider mites from the Henderson and Fordhook cultivar, respectively. Predator larvae were reared in Petri dish arenas $(90 \times 25 \mathrm{~mm}, \mathrm{~W} \times \mathrm{H}$, with screened lids), at a density of 20 first instars. Arenas were stored inside a growth chamber at $23^{\circ} \mathrm{C}, 60 \% \mathrm{RH}$, and $16 \mathrm{~h}$ photophase. Immature predators remained in the same arenas until adult emergence. Newly emerged females were confined with males in clear plastic containers $(16 \times 12$ $\times 6 \mathrm{~cm}, \mathrm{~L} \times \mathrm{W} \times \mathrm{H}$, with screened lids) on mite-infested Henderson or Fordhook leaves (the same treatment used for immature stages) for 4 days, to allow mating. A small ball of cotton, moistened with distilled water, was in each arena for beetles. Containers were stored inside a growth chamber under the same conditions of temperature, humidity, and photophase as previously described. After this, we placed the females, now presumed to have mated, individually in Petri dish arenas provisioned with 1-2 mite-infested leaves. We ensured that leaves harbored enough mites to meet the daily nutritional requirements of mothers and replaced old leaves with new leaves each day. We conducted one trial of this experiment with sample size of 10 mothers in the low quality and 10 mothers in the high quality prey treatments. We consistently used young mothers of approximately the same age in the two treatments and examined eggs laid by them over three consecutive days (19-21 July 2010), near the beginning of their oviposition period. Each day we harvested single eggs using a fine, camel hair paintbrush. The laying of eggs singly, rather than in batches, is typical for most, if not all, species in the genus Stethorus [14]. We transferred eggs to clean Petri dishes. They laid from 2 to 9 eggs per day (132 total eggs) in the low quality and 4 to 9 eggs per day (182 total eggs) in the high quality treatments. Each day, we measured the size (length, width) of freshly laid eggs of each 
female using an Olympus SZ11 zoom stereomicroscope and computer-based imaging software (Image Pro Plus, Media Cybernetics Inc., MO, USA). We also determined the effects of date of collection of eggs (harvest date) and prey quality on egg length. We calculated mean egg volume $(V)$ using the formula for a prolate spheroid, $V=(4 / 3) \pi a^{2} b$, where $a$ represents half the mean egg width and $b$ represents half the mean egg length, after Kajita and Evans [20]. We did not measure body size of mothers in this experiment.

2.3. Maternal Size and Egg Size. In a separate experiment to determine if egg size related to maternal size, we reared S. punctillum mothers from the time of eclosion in Petri dish arenas $(90 \times 25 \mathrm{~mm}, \mathrm{~W} \times \mathrm{H}$, with screened lids $)$, at a density of 20 first instars per arena, on spider mites from Fordhook lima bean only. Arenas were stored inside a growth chamber $\left(23^{\circ} \mathrm{C}, 60 \% \mathrm{RH}, 16 \mathrm{~h}\right.$ photophase $)$ and immature predators remained in the same arenas until adult emergence. Newly emerged females were confined with males in clear plastic containers $(16 \times 12 \times 6 \mathrm{~cm}, \mathrm{~L} \times$ $\mathrm{W} \times \mathrm{H}$, with screened lids) on mite-infested Fordhook leaves for 4 days, to allow mating. Procedures of maintaining predators were the same as those detailed in the previous experiment. In this experiment, egg size and maternal size were determined using a stereomicroscope and imaging software (as before). Based on allometry [28], we assumed that the hind femur was a good estimate of the body size of S. punctillum mothers. Therefore, we correlated the length of the mother's hind femur to the length, volume, as well as perimeter of her eggs. In order to lighten the workload, we conducted two identical trials with 18 mothers in trial 1 and 22 mothers in trial 2 . We consistently used young mothers of approximately the same age in the two trials and examined eggs laid by them, from near the beginning of the oviposition sequence until they ceased producing eggs or died. We harvested eggs from arenas from late February to early April 2010 in trial 1 and from early May to early July 2011 in trial 2. The total number of eggs laid per mother over the trial 1 test period ranged from 11 to 176 eggs (69 eggs, average) and an average of 15 harvest dates per mother, yielding an average of 4 eggs per date. The total production from 18 mothers was 1,218 eggs in trial 1 . The total number of eggs laid per mother during trial 2 ranged from 9 to 128 eggs (48 eggs, average) and an average of 11 harvest dates per mother, yielding an average of 4 eggs per date. The total production from 22 mothers was 1,061 eggs in trial 2 . We transferred eggs to clean Petri dishes, measured the size of freshly laid eggs using a stereomicroscope and imaging software (as before). We did not determine the effects of harvest date on egg length. We did calculate egg volume from mean egg length and egg width (as before).

2.4. Egg Size and Hatching. To determine if egg size influenced hatching, we monitored the days required to hatch and the percent hatch of eggs laid by the 22 mothers in trial 2 of the previous experiment. We placed eggs laid by each mother each day into a clean Petri dish $(40 \times 10 \mathrm{~mm}, \mathrm{~W} \times \mathrm{H}$, with unscreened lids) and checked each dish daily for egg hatch, and promptly removed any hatching first instars. For each mother, we compared the number eggs that hatched with those that did not hatch and correlated hatch time (days) and percent hatch rate with egg length. As an additional analysis, we assigned eggs into size categories (short, 341-360 $\mu \mathrm{m}$; intermediate, $361-380 \mu \mathrm{m}$; long, $381-400 \mu \mathrm{m}$ ) to determine if size affected hatch rate or hatch time. The sample size was 22 mothers (1,032 hatched eggs; 29 unhatched eggs).

2.5. Statistical Analysis. We used the Student's $t$-test to determine the effect of prey quality on egg length and volume and a two-factor analysis of variance (2-way ANOVA) to determine the effect of harvest date and prey quality, with interactions, on egg length and the Holm-Sidak method to separate means, if necessary. We used a Pearson Product Moment Correlation to determine if maternal size correlated with egg size, and a Simple Linear Regression to estimate a functional relationship between femur length and egg size. We also used the Student's $t$-test to compare the length of hatched versus unhatched eggs and a Pearson Product Moment Correlation to determine if hatch time or hatch rate correlated with mean egg length. We used a one-factor analysis of variance (1-way ANOVA) to detect any differences in hatch time or hatch rate between egg categories (short, intermediate, or long) and the Holm-Sidak method to separate means, if necessary. We analyzed data following a randomized design, and square root transformed absolute data and arcsine transformed percentage data prior to analysis [29]. Mean values were considered significantly different when $P \leq 0.05$. We used Sigma Stat 3.0.1 (Systat Software Inc., Richmond, CA, USA) software for analysis of data. All data presented herein represent nontransformed values.

\section{Results}

In our first experiment, egg length and volume were greater for mothers feeding on high quality rather than low quality prey for pooled data (egg length, $t=5.0 ; \mathrm{df}=18 ; P<$ 0.001 ; Figure 1(a); egg volume, $t=8.0 ; \mathrm{df}=18 ; P<0.001$; Figure 1(b)). The date that eggs were harvested from mothers did not affect egg length $(F=0.90 ; \mathrm{df}=2,308 ; P=0.41)$. The mean \pm SEM egg lengths on consecutive dates were $391.5 \pm$ $3.6 \mu \mathrm{m}$ (day 1 ), $384.8 \pm 2.7 \mu \mathrm{m}$ (day 2 ), and $381.6 \pm 3.0 \mu \mathrm{m}$ (day 3 ) in the high quality treatment and $370.4 \pm 3.2 \mu \mathrm{m}$ (day 1), $369.2 \pm 2.8 \mu \mathrm{m}$ (day 2), and $373.2 \pm 3.4 \mu \mathrm{m}$ (day 3 ) in the low quality treatment. Longer eggs resulted from mothers fed high quality rather than low quality prey $(F=31.9$; $\mathrm{df}=1$, 308; $P<0.001)$ with no interaction between harvest date and prey quality $(F=1.8 ; \mathrm{df}=2,308 ; P=0.17)$.

In our second experiment, hind femur length correlated with mean length, volume, and perimeter of eggs (Table 1). Mean egg size increased as femur length increased (Figures $2(a)$ and 2(b)). Note that egg size is large relative to femur size in this species (Figures 3(a) and 3(b)). The size of eggs laid by mothers was variable, but significant changes in egg size within and between harvest dates were not apparent. 


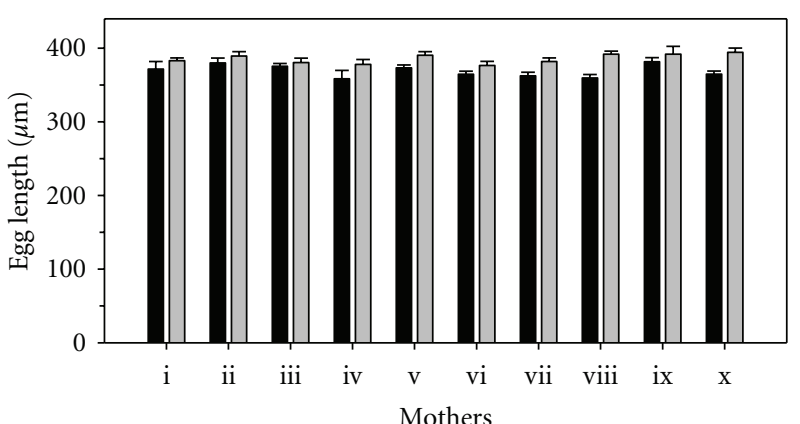

Low quality prey
High quality prey

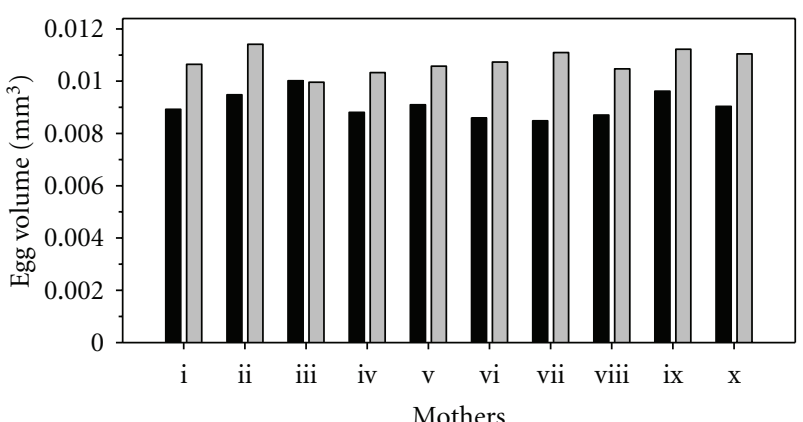

Low quality prey $\square$ High quality prey

(a)

(b)

FIGURE 1: Mean \pm SEM length (a) and volume (b) of eggs laid by 10 predators (mothers) fed high quality or low quality prey over combined harvest dates. Egg volume generated from mean egg length and mean egg width. High quality or low quality prey represent spider mites that fed on foliage of Fordhook or Henderson lima bean, respectively.

TABLE 1: Linear regression equations and ANOVA statistics for the relationship of egg size versus femur length of predators (mothers).

\begin{tabular}{lccccccc}
\hline Trial & Egg size & Equation & $F$ & df & $P$ & $r$ \\
\hline 1 & Length & $Y=162.6+0.6 X$ & 6.0 & 1,16 & 0.03 & 0.52 & 0.27 \\
& Volume & $Y=-0.02+0.007 X$ & 9.0 & 1,16 & 0.008 & 0.60 & 0.36 \\
& Perimeter & $Y=517.4+1.3 X$ & 10.4 & 1,16 & 0.005 & 0.63 & 0.39 \\
2 & Length & $Y=110.7+0.7 X$ & 25.6 & 1,20 & $<0.001$ & 0.75 & 0.56 \\
& Volume & $Y=0.003+0.00002 X$ & 4.6 & 1,20 & 0.045 & 0.43 & 0.19 \\
& Perimeter & $Y=468.8+1.4 X$ & 41.4 & 1,20 & $<0.001$ & 0.82 & 0.67 \\
\hline
\end{tabular}

Simple linear regression, $Y=b_{o}+b_{1} X ; Y$ represents egg length, volume or perimeter; $b_{o}$ and $b_{1}$ represent the constant term and slope, respectively; $X$ represents femur length. Length and perimeter are in $\mu \mathrm{m}$ units. Volume is in $\mathrm{mm}^{3}$ units. Regression equations reflect nontransformed data. See scatterplot (Figure 2) with regression lines of egg length versus femur length. Regression lines of egg perimeter versus femur length and egg volume versus femur length not plotted.

In our final experiment, the length of eggs did not correlate with the time required for first instar larvae to hatch $(r=0.03 ; P=0.8 ; n=22$; Figure $4(\mathrm{a}))$ or with percent hatch rate $(r=0.19 ; P=0.4 ; n=22$; Figure $4(\mathrm{~b}))$. Assignment of eggs to categories (short, intermediate, long) did not reveal any significant effect of size on hatch time $(F=0.9 ; \mathrm{df}=2$, $19 ; P=0.4)$ or hatch rate $(F=0.6 ; \mathrm{df}=2,19 ; P=0.5)$ in this study (Table 2). First instar larvae usually hatched within 5 to 6 days after the day of oviposition. Hatch rate was relatively high, ranging from $89 \%$ to $100 \%$. There was no difference in the length of eggs that hatched versus did not hatch $(t=$ $1.1 ; \mathrm{df}=34 ; P=0.26)$. The mean \pm SEM length of hatched and unhatched eggs was $370.4 \pm 2.3 \mu \mathrm{m}$ and $375.4 \pm 3.9 \mu \mathrm{m}$, respectively. Just 14 out of 22 mothers laid eggs that failed to hatch.

\section{Discussion}

Our observation that $S$. punctillum mothers produce larger eggs when fed from birth on high quality prey (spider mites on Fordhook lima bean) suggests that the nutritional content of prey has important consequences on the growth of this predator. In our prey quality experiment, we did not determine the body size of mothers. At the time, we did not think it was necessary to record their size, since our previous research clearly showed that prey quality altered the growth and development of $S$. punctillum immatures; smaller immatures resulted from feeding on low-quality rather than high-quality prey [27]. The concentration of linamarin, a cyanogenic glycoside purportedly used by the plant in defending itself against herbivory, is much greater in Henderson than in Fordhook lima beans [30]. Linamarin reduces the amount of nutrients (including soluble protein) that $T$. urticae can extract from lima bean foliage, resulting in prey of lower quality for $S$. punctillum, reducing growth rate and body size, but not fecundity or longevity [27]. Molecules that plants use in defense against herbivory might pass up the food chain [31] and reduce the quality of prey for the predator [32] or have no negative effects on the predator [33]. Prey quality can affect egg size in other natural enemies. Carabid beetles that consume high quality prey produce larger eggs than those that consume low quality prey [8]. Staphylinid beetles that consume aphids of high quality produce larger eggs [7]. No prior study demonstrates that prey quality affects the size of individual eggs of coccinellids. One study does demonstrate that low quality prey reduces the size of egg batches of coccinellids [9]. 


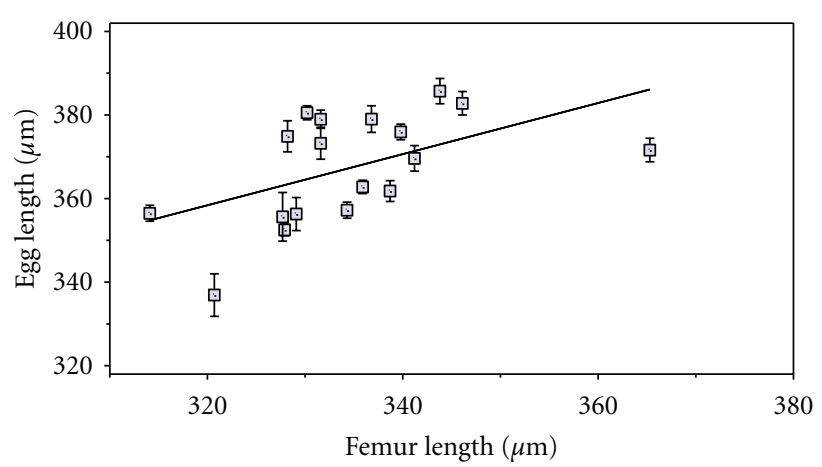

(a)

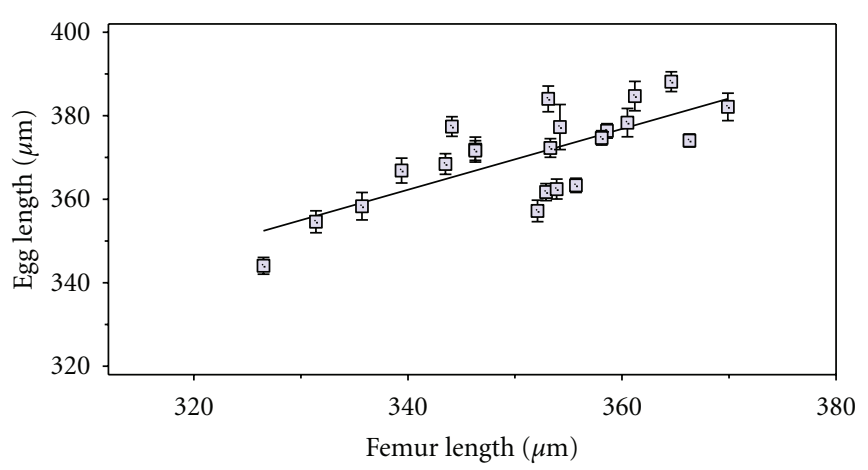

(b)

FIgURE 2: Mean \pm SEM egg length versus femur length of combined mothers fed only high quality prey in trials 1 (a) and 2 (b) over combined harvest dates. The regression line defines a significant relationship between mean egg length $(Y)$ versus femur length $(X)$, simple linear regression $Y=b_{o}+b_{1} X$. In trial $1: b_{o}, 162.6 ; b_{1}, 0.6 ; r^{2}=0.27 ; n, 18$ observations (mothers). In trial $2: b_{o}, 114.6 ; b_{1}, 0.7 ; r^{2}=0.55 ; n$, 22 observations (mothers). Refer to Table 1 for the ANOVA statistics of each regression analysis.

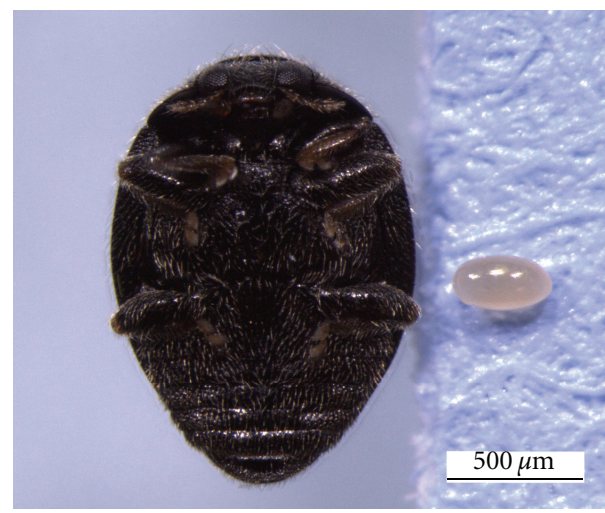

(a)

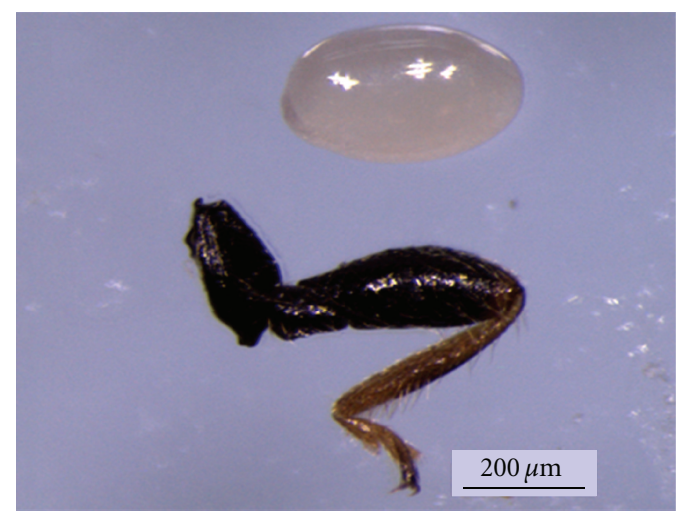

(b)

FIGURE 3: Ventral view of a mother with freshly laid egg (a) and dissected femur of another mother adjacent to one of her eggs (b).

Our observations that $S$. punctillum body size correlates with mean egg size (even when predators are reared on the same high quality prey) may suggest that the quantity of prey nutrients that developing larvae ingest and metabolize is fine-tuned with the size they attain as adults and the average size of their progeny (eggs). To our knowledge, no one has examined the relationship between body size and egg size in S. punctillum, or any other acariphagous lady beetle, so a mechanism that explains this positive maternaloffspring relationship in this lady beetle is unavailable. At the intraspecific level, body size of females of a given species can scale positively, negatively, or not at all with egg size [16-19]. When Kajita and Evans [20] combined data on five aphidophagous coccinellids, mean egg size (volume) related significantly to maternal body weight, with no significant relationship among species. Investigators report a lack of correlation between body size and egg size in carabid tiger beetles [21], colydiid beetles [22], and spiders [19].

Stethorus punctillum mothers are sensitive to changes in the quantity of prey (tetranychid mites) available to them. Any significant decrease in food supply available to ovipositing mothers can halt subsequent egg laying behavior and oogenesis [EWR \& ZW, unpublished data], [34]. Therefore, the constant availability of nutritious prey is critical to the reproductive success of this specialized predator.

The small size of $S$. punctillum adults may place constraints on (1) the number of ovarioles within their ovaries, (2) the rate of oogenesis, (3) the capacity to store many eggs, and (4) the rate at which they lay eggs. S. punctillum emerge as adults with no developing eggs in their ovaries, and all adult females are limited to only two ovarioles per ovary [EWR, unpublished data], [35]. Consequently, mothers might invest more resources (nutrients) into producing fewer large eggs rather than many small eggs to compensate for these limitations.

Our observation that egg size does not influence hatch time or hatch rate is encouraging and suggests that egg size is not a good predictor of egg viability. Egg size also does not influence hatch time of the seven spot ladybird beetle C. septempunctata L. [10]. The moderately high hatch rates evidenced in this study are the expectation for species, such as Stethorus spp., which invest considerable resources into producing fewer, larger eggs. The fact that $S$. punctillum mothers lay eggs singly and do not experience high rates of 


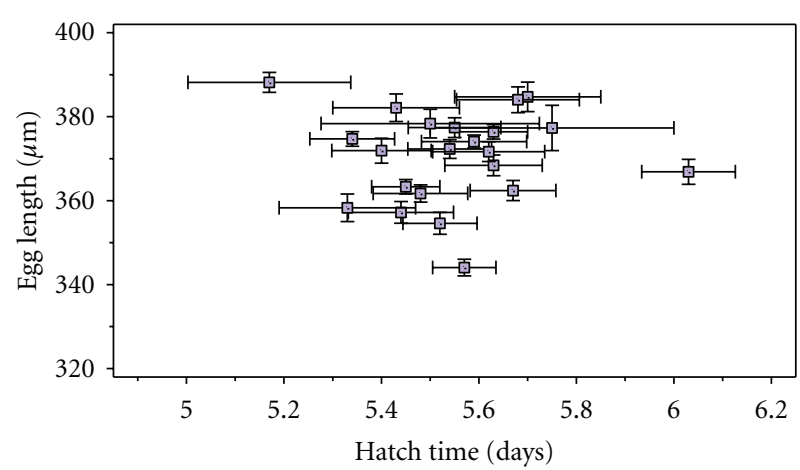

(a)

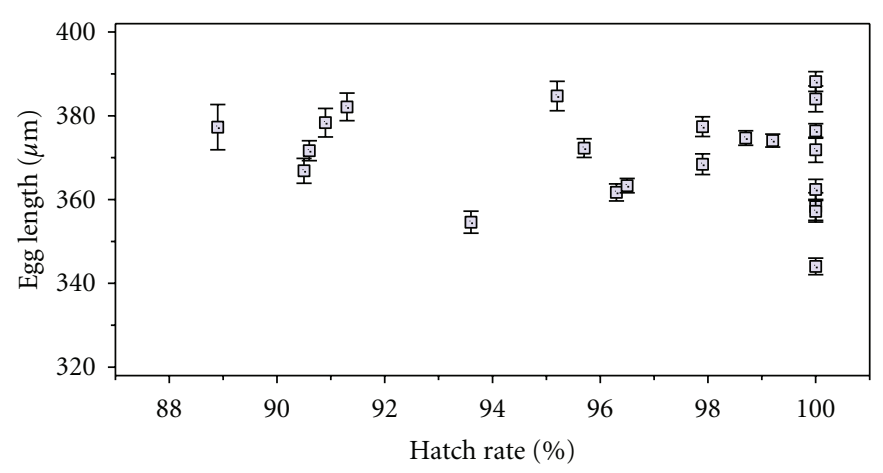

(b)

FIgURE 4: Mean \pm SEM egg length versus mean \pm SEM hatch time (a) or hatch rate (b) of eggs from 22 mothers, from trial 2 of the maternal size-egg size experiment. Mothers fed high quality prey only.

TABLE 2: Mean \pm SEM hatch rate and hatch time of predator eggs in relation to size category.

\begin{tabular}{lcccc}
\hline $\begin{array}{l}\text { Egg length range } \\
(\mu \mathrm{m})\end{array}$ & Category & Hatch rate $(\%)$ & $\begin{array}{c}\text { Hatch time } \\
(\text { days })\end{array}$ & Mothers $(n)$ \\
\hline $341-360$ & Short & $98.4 \pm 1.60$ & $5.46 \pm 0.05$ & 4 \\
$361-380$ & Intermediate & $95.9 \pm 1.07$ & $5.58 \pm 0.05$ & 14 \\
$381-400$ & Long & $96.6 \pm 2.10$ & $5.49 \pm 0.12$ & 4 \\
\hline
\end{tabular}

Only hatched eggs represented in this table.

cannibalism fits an oviposition strategy of investing heavily into eggs. We did not determine if S. punctillum larvae hatching from short rather than intermediate or long eggs were less likely to reach the pupal stage in this study. Others have shown that larvae of two predatory carabids, $P$. cupreus and $P$. melanarius, which hatch from large rather than small eggs, lived longer [8]. Larger-sized first instar larvae of a staphylinid $A$. bilineata survive longer and are more efficient at finding hosts than smaller-sized ones [24].

In conclusion, S. punctillum mothers that consume highquality prey during the larval and adult stages generate larger eggs. Maternal body size affects progeny size; egg size increases as femur length increases. Longer eggs do not develop more rapidly or hatch at higher rates than shorter eggs or vice versa. Further research could explore the influence of feeding rate and oogenesis on the size relationship between $S$. punctillum mothers and their progeny. Since our knowledge of body size-egg size relationships is limited to only several coccinellid species, further investigations on the subtle effects of nutrition on predator size are warranted. Only then can we identify patterns that would allow us to predict the degree that coccinellid mothers will invest resources (nutrients) into eggs rather than into sustaining their lifespan.

\section{Acknowledgments}

The authors thank John J. Sloggett and Jean-Louis Hemptinne for insightful reviews of an earlier version of this paper. They thank M. Guadalupe Rojas for bean foliage infested with spider mites. Anonymous reviewers gave recommendations that improved this paper. The United States Government has the right to retain a nonexclusive, royalty-free license in and to any copyright of this paper. This paper reports the results of research only. Mention of a commercial or proprietary product does not constitute an endorsement of the product by the United States Department of Agriculture. USDA is an equal opportunity provider and employer.

\section{References}

[1] J. Bernardo, "The particular maternal effect of propagule size, especially egg size: patterns, models, quality of evidence and interpretations," American Zoologist, vol. 36, no. 2, pp. 216236, 1996.

[2] C. W. Fox and M. E. Czesak, "Evolutionary ecology of progeny size in arthropods," Annual Review of Entomology, vol. 45, pp. 341-369, 2000.

[3] T. A. Mousseau and C. W. Fox, "The adaptive significance of maternal effects," Trends in Ecology and Evolution, vol. 13, no. 10, pp. 403-407, 1998.

[4] C. C. Smith and S. D. Fretwell, "The optimal balance between size and number of offspring," American Naturalist, vol. 108, pp. 499-506, 1974.

[5] D. Berrigan, "The allometry of egg size and number in insects," Oikos, vol. 60, no. 3, pp. 313-321, 1991.

[6] R. K. Vijendravarma, S. Narasimha, and T. J. Kawecki, "Effects of parental larval diet on egg size and offspring traits in Drosophila," Biology Letters, vol. 6, no. 2, pp. 238-241, 2010.

[7] A. Kyneb and S. Toft, "Effects of maternal diet quality on offspring performance in the rove beetle Tachyporus hypnorum," Ecological Entomology, vol. 31, no. 4, pp. 322-330, 2006. 
[8] H. Wallin, P. A. Chiverton, B. S. Ekbom, and A. Borg, "Diet, fecundity and egg size in some polyphagous predatory carabid beetles," Entomologia Experimentalis et Applicata, vol. 65, no. 2, pp. 129-140, 1992.

[9] A. F. G. Dixon, Insect Predator-Prey Dynamics: Ladybird Beetles and Biological Control, Cambridge University Press, Cambridge, UK, 2000.

[10] A. F. G. Dixon and Y. Guo, "Egg and cluster size in ladybird beetles (Coleoptera: Coccinellidae): the direct and indirect effects of aphid abundance," European Journal of Entomology, vol. 90, pp. 457-463, 1993.

[11] A. F. G. Dixon and J. L. Hemptinne, "Body size distribution in predatory ladybird beetles reflects that of their prey," Ecology, vol. 82, no. 7, pp. 1847-1856, 2001.

[12] A. Honěk, A. F. G. Dixon, and Z. Martinkova, "Body size, reproductive allocation, and maximum reproductive rate of two species of aphidophagous Coccinellidae exploiting the same resource," Entomologia Experimentalis et Applicata, vol. 127, no. 1, pp. 1-9, 2008.

[13] J. J. Sloggett, "Weighty matters: body size, diet and specialization in aphidophagous ladybird beetles (Coleoptera: Coccinellidae)," European Journal of Entomology, vol. 105, no. 3, pp. 381-389, 2008.

[14] J. Chazeau, "Predaceous insects," in Spider Mites: Their Biology, Natural Enemies and Control, W. Helle and M. W. Sabelis, Eds., vol. 1, pp. 211-246, Elsevier Science, Amsterdam, The Netherlands, 1985.

[15] A. Honěk, "Life history and development," in Ecology of Coccinellidae, I. Hodek, A. Honěk, P. Ceryngier, and I. Kovár, Eds., pp. 61-93, Kluwer Academic, Dordrecht, The Netherlands, 1996.

[16] C. Wiklund and B. Karlsson, "Egg size variation in satyrid butterflies: adaptive vs historical, "Bauplan", and mechanistic explanations," Oikos, vol. 43, no. 3, pp. 391-400, 1984.

[17] K. Ito, "Egg-size and -number variations related to maternal size and age, and the relationship between egg size and larval characteristics in an annual marine gastropod, Haloa japonica (Opisthobranchia; Cephalaspidea)," Marine Ecology Progress Series, vol. 152, no. 1-3, pp. 187-195, 1997.

[18] K. Fischer, B. J. Zwaan, and P. M. Brakefield, "How does egg size relate to body size in butterflies?” Oecologia, vol. 131, no. 3, pp. 375-379, 2002.

[19] C. D. Skow and E. M. Jakob, "Effects of maternal body size on clutch size and egg weight in a pholcid spider (Holocnemus pluchei)," Journal of Arachnology, vol. 31, no. 2, pp. 305-308, 2003.

[20] Y. Kajita and E. W. Evans, "Relationships of body size, fecundity, and invasion success among predatory lady beetles (Coleoptera: Coccinellidae) inhabiting alfalfa fields," Annals of the Entomological Society of America, vol. 103, no. 5, pp. 750756, 2010.

[21] S. A. Juliano, "The effects of body size on mating and reproduction in Brachinus lateralis (Coleoptera: Carabidae)," Ecological Entomology, vol. 10, no. 3, pp. 271-280, 1985.

[22] K. Togashi and M. Itabashi, "Maternal size dependency of ovariole number in Dastarcus helophoroides (Coleoptera: Colydiidae)," Journal of Forest Research, vol. 10, no. 5, pp. 373 376, 2005.

[23] G. S. McIntyre and R. H. Gooding, "Egg size, contents, and quality: maternal-age and -size effects on house fly eggs," Canadian Journal of Zoology, vol. 78, no. 9, pp. 1544-1551, 2000.
[24] G. Boivin and M. J. Gauvin, "Egg size affects larval performance in a coleopteran parasitoid," Ecological Entomology, vol. 34, no. 2, pp. 240-245, 2009.

[25] J. C. van Lenteren, "Commercial availability of biological control agents," in Quality Control and Production of Biological Control Agents, Theory and Testing Procedures, J. C. van Lenteren, Ed., pp. 167-179, CABI, London, UK, 2003.

[26] D. J. Biddinger, D. C. Weber, and L. A. Hull, "Coccinellidae as predators of mites: Stethorini in biological control," Biological Control, vol. 51, no. 2, pp. 268-283, 2009.

[27] E. W. Riddick, M. G. Rojas, and Z. Wu, "Lima bean-lady beetle interactions: spider mite mediates sublethal effects of its host plant on growth and development of its predator," ArthropodPlant Interactions, vol. 5, pp. 287-296, 2011.

[28] D. L. Stern and D. J. Emlen, "The developmental basis for allometry in insects," Development, vol. 126, no. 6, pp. 10911101, 1999.

[29] J. H. Zar, Biostatistical Analysis, Prentice Hall, New Jersey, NJ, USA, 4th edition, 1999.

[30] M. G. Rojas and J. A. Morales-Ramos, "Tri-trophic level impact of host plant linamarin and lotaustralin on Tetranychus urticae and its predator Phytoseiulus persimilis," Journal of Chemical Ecology, vol. 36, no. 12, pp. 1354-1362, 2010.

[31] L. Witte, A. Ehmke, and T. Hartmann, "Interspecific flow of pyrrolizidine alkaloids. From plants via aphids to ladybirds," Naturwissenschaften, vol. 77, no. 11, pp. 540-543, 1990.

[32] C. Pratt, T. W. Pope, G. Powell, and J. T. Rossiter, "Accumulation of glucosinolates by the cabbage aphid Brevicoryne brassicae as a defense against two coccinellid species," Journal of Chemical Ecology, vol. 34, no. 3, pp. 323-329, 2008.

[33] K. L. Giles, R. C. Berberet, A. A. Zarrabi, and J. W. Dillwith, "Influence of alfalfa cultivar on suitability of Acyrthosiphon kondoi (Homoptera: Aphididae) for survival and development of Hippodamia convergens and Coccinella septempunctata (Coleoptera: Coccinellidae)," Journal of Economic Entomology, vol. 95, no. 3, pp. 552-557, 2002.

[34] W. L. Putman, "Bionomics of Stethorus punctillum Weise (Coleoptera: Coccinellidae) in Ontario," Canadian Entomologist, vol. 87, pp. 9-33, 1955.

[35] J. G. Robertson, "Ovariole numbers in Coleoptera," Canadian Journal of Zoology, vol. 39, pp. 245-263, 1961. 

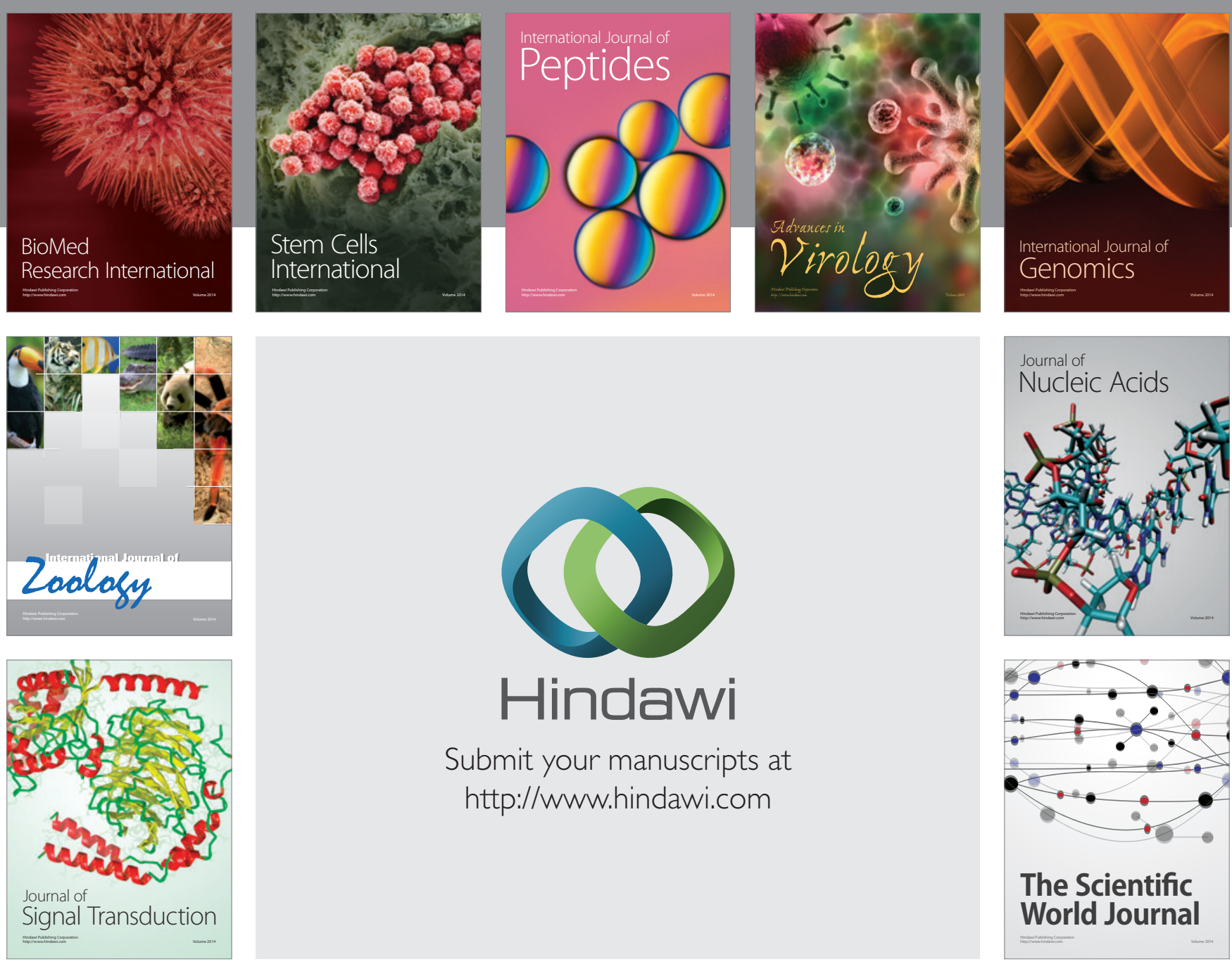

Submit your manuscripts at

http://www.hindawi.com
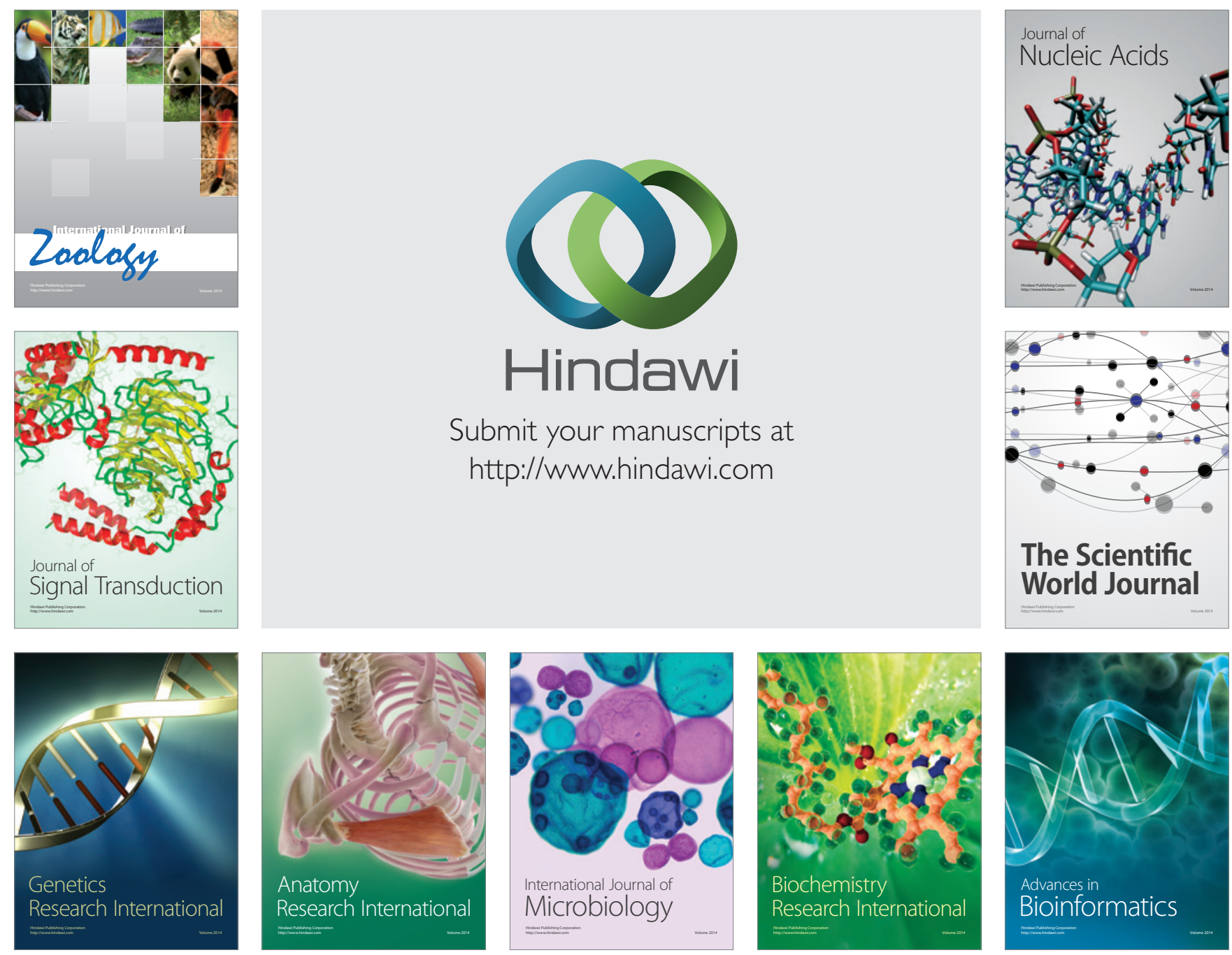

The Scientific World Journal
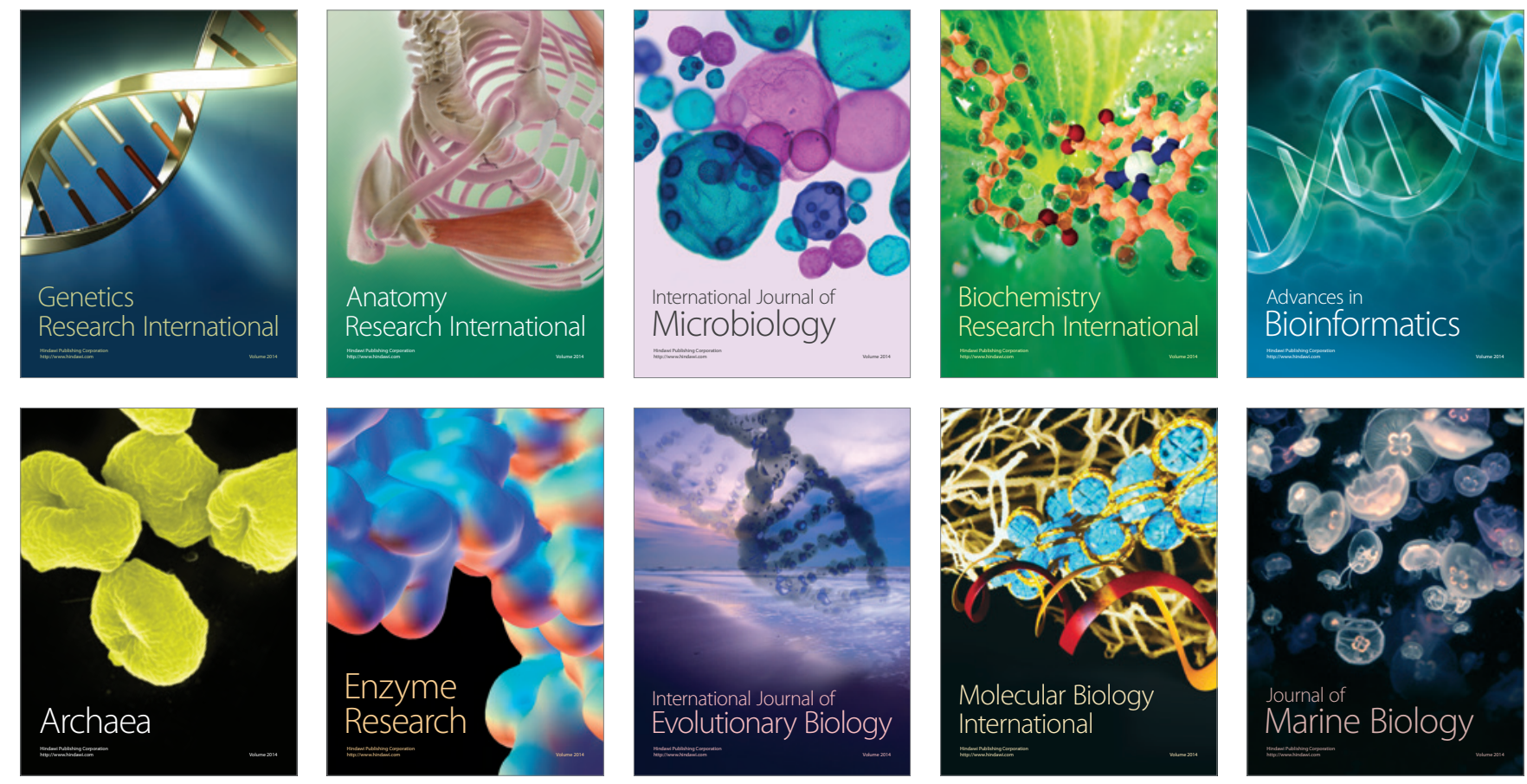